\title{
Treatment of Uncomplicated Malaria among Under-Five Children: A Systematic Review
}

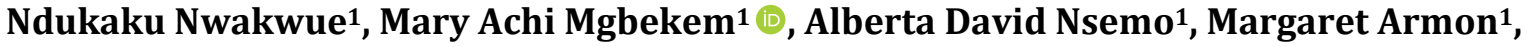 \\ Regina Ella1, Ifreke Willie Akpan², Pricilla Adrew-Bassey² \\ ${ }^{1}$ Department of Nursing Science, University of Calabar, Calabar, Nigeria \\ ${ }^{2}$ University of Calabar Teaching Hospital, Calabar, Nigeria \\ Email:ndukacn@unical.edu.ng
}

How to cite this paper: Nwakwue, N., Mgbekem, M.A., Nsemo, A.D., Armon, M., Ella, R., Akpan, I.W. and Adrew-Bassey, P. (2020) Treatment of Uncomplicated Malaria among Under-Five Children: A Systematic Review. Health, 12, 378-395.

https://doi.org/10.4236/health.2020.124031

Received: September 24, 2019

Accepted: April 21, 2020

Published: April 24, 2020

Copyright $\odot 2020$ by author(s) and Scientific Research Publishing Inc. This work is licensed under the Creative Commons Attribution International License (CC BY 4.0).

http://creativecommons.org/licenses/by/4.0/

\begin{abstract}
Most uncomplicated malaria dominated countries have embraced the recommended first-line treatment of uncomplicated malaria. Artemisinin-based combination therapies such as Artemether-Lumefantrine, Artesunate + Amodiaquine and Dihydroartemisinin-Piperaquine have shown to be effective with Artemether-Lumefantrine and considered the most effective and approved by WHO. The study collected and reviewed recent randomized controlled trials for the treatment of uncomplicated malaria under five children. Eligibility criteria for the selected studies were based on the use of tools such as PICO (T) and data extraction tools such as REPOSE guidelines, PRISMA statement and eligibility criteria. This study includes only RCTs on the treatment of uncomplicated malaria under $5 \mathrm{~s}$. Data was analyzed through comparative-narrative analysis. This study found 8 studies. Selected studies had a total of 10,682 participants within the age range of 0 - 59 months with the diagnosis of uncomplicated malaria and an MCP range of $2000-200,000$ treated with different antimalarial drugs. Artesunate + Amodiaquine and Dihydroartemisinin-Piperaquine and Artemether-Lumefantrine drugs were found to be consistent in the treatment of uncomplicated malaria under $5 \mathrm{~s}$ within three days. Findings show that Artemether-Lumefantrine, Artesunate + Amodiaquine and Dihydroartemisinin-Piperaquine were the best drugs of choice due to their fast rate in fever reduction and parasite clearance. The efficacy of Artesunate + Amodiaquine and Dihydroartemisinin-Piperaquine is comparable to Dihydroartemisinin-Piperaquine. The study concludes that Artesunate + Amodiaquine and Dihydroartemisinin-Piperaquine can also be drugs of choice along with the well-known and utilized Artemether-Lumefantrine combination because of the fever reduction and parasite clearance within the first three days duration.
\end{abstract}




\section{Keywords}

Malaria, Under-Five, Antimalarial, Treatment, Uncomplicated Malaria, ACTs

\section{Background of Study}

Malaria constitutes a global public health challenge despite the availability and affordability of its treatment and preventive measures. The World Health Organisation (WHO) [1] report revealed that malaria was responsible for an estimated 660,000 people morbidity and mortality comprised mostly of children under-five years in Sub-Saharan Africa. In another report (WHO) [2] report, Nigeria and the Republic of Congo accounted for over $40 \%$ of the estimated global malaria deaths. The Federal Ministry of Health (FMH) [3] suggests that malaria accounts for one quarter of all death cases in Africa and one of the world's highest malaria associated death rate with one in six children dying from malaria related illness before their fifth birthday. It is, pertinent to state that it is difficult to attribute the cause of death of under-five children in these countries to malaria alone without considering other existing conditions such as malnutrition, diarrhoea, respiratory tract infections (WHO) [4]. According to the National Population Commission [5], the endemic nature of malaria in Nigeria is very high with nearly 110 million cases diagnosed clinically annually with $25 \%$, $11 \%$ and $30 \%$ of infant mortality, maternal mortality and under-five mortality respectively associated with malaria. It is important to state that the incidence of uncomplicated malaria in Sub-Sahara Africa always coexists with malnutrition which is a public health challenge [6] [7].

Following the birth of programs from International Organisations like Roll back malaria, Global Fund, UNICEF and non-profit international agencies, much emphasis is being directed towards the treatment of uncomplicated malaria in under-five [8]. Consequently, these bodies are faced with serious challenge of combating ACTs (Artemisinin-based combination therapies) resistance [9]. ACTs such as Artemether-Lumefantrine and Artesunate + Amodiaquine combinations continue to top the list in the multiple first-line treatment [10]. According to WHO [11] "the therapeutic efficacy studies are prospective evaluation of patients clinical and parasitological responses to directly observe treatment of uncomplicated malaria”. WHO further recommends that all national malaria control programs (NMCP) should adopt antimalarial medicines with a parasitological cure rate of over $95 \%$. WHO [11], however stated that there should be a change in the national treatment policy if the total treatment failure proposition is $\geq 10 \%$. This policy statement thus initiated the establishment of a global surveillance system to monitor the emergence of resistance to antimalarial agents [11]. WHO, therefore continues to steer the driving wheel in the treatment of uncomplicated malaria through the development of drug policies in all WHO regions. Such policies have contributed to the withdrawal of some drugs 
for the treatment of malaria. The objective of this study was thus aimed at reviewing randomised controlled trials (RCTs) published studies on the treatment of uncomplicated malaria.

\section{Materials and Methods}

A systematic review design was used to identify, collect and analyse RCTs. Data for this study were from RCTs sourced from biographic database and the following search engines: Biomed central, Discover, Embase, Cochrane Library, and Science Direct. Only data from studies published in reputable and peer- reviewed journals were used. RCTs were restricted to those published or transcribed in English on the treatment of uncomplicated malaria in under-five children [12].

\subsection{Study Protocol}

Uncomplicated malaria is complex especially in under-five children. This is because children cannot verbalise the signs and symptoms they experience. The study protocol as shown on Figure 1 adopted and carried out in six stages according to the Cochrane's protocol format [13] as shown below.

\subsection{Study Selection}

The process of identifying RCTs with the aim to answer the research question is rigorous. However, the selection was done by the authors using the Cochrane's tool of assessing bias and the PRISMA checklist as a guide [14] [15] and the CONSORT recommendation selection process. The RCTs for this study was on studies examining the treatment of uncomplicated malaria in under-five children [16].

\subsection{Sampling Technique}

A purposive sampling technique guided by Cochrane's tool for assessing bias was employed for the study since a purposive sampling technique is a nonprobability sampling tool usually based on the author's judgement even though it is highly inflicted by the author's bias [17]. The sampling technique was done after

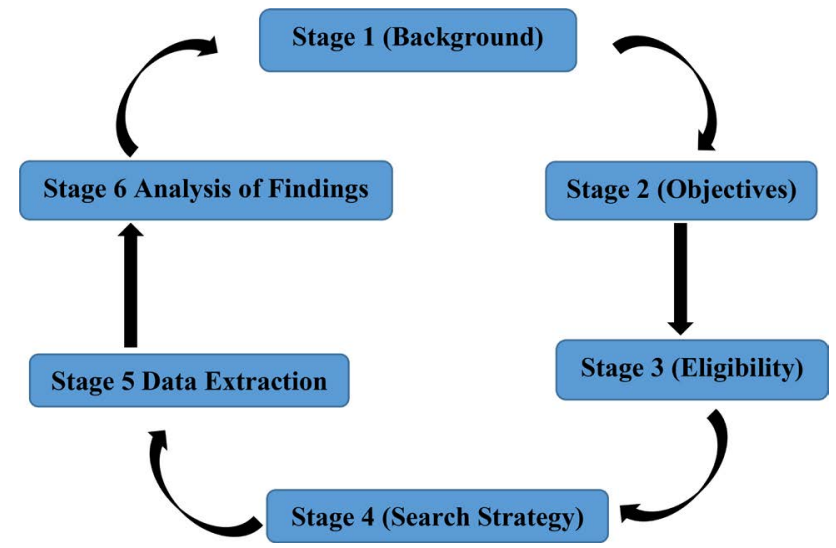

Figure 1. Systematic review protocol for the study adopted from Higgins et al. [13]. 
eligibility criteria were conducted to know the RCTs that meets the study's criteria.

\subsection{Data Collection}

Data source triangulation was the primary means of data collection. Data was collected through electronic means from databases, search engines and manually from the [18] [19]. Data extraction was based on the eligibility criteria as shown on Table 1, study design, age of participants; intervention, attrition and detection bias [20]. Randomization was assessed in relation to allocation, concealment, blinding, reporting of outcomes and follow ups that helped in removing bias and missing data [21].

\subsection{Data Extraction}

To achieve the aims and objective of the study, data was extracted using some data extraction tools such as PRISMA statement, REPOSE guidelines, PICOT, eligibility criteria, report characteristics of each included study like language, publication and year [27] [28]. This process of data extraction helped re-extract individual studies that were skipped during the first data collection. Data extraction was done solely by the authors. However, data extraction was done in duplicates to identify errors and minimise subjectivity from interpreting data [12].

\subsection{Ethical Consideration}

The ethical consideration of systematic reviews is authorship which is of different types: falsification, fabrication and plagiarism of RCTs. Considering the fact that systematic reviews integrity is highly threatened by these aforementioned [29] [30] this study maintained high degree of transparency as stated in the Cochrane's ethics of publishable reviews [31].

\subsection{Description of Included Studies}

A total of 6 electronic databases and search engines where searched. An aggregate of 6315 studies on the treatment of malaria was found (Figure $2 \&$ Table 2)

\section{Analysis}

With the use of Cochrane's tool for assessing bias, 8 studies were identified and analysed.

Table 1. Eligibility criteria for the study.

2.5 Eligibility Criteria: The eligibility criteria for studies used in this Exclusion criteria

study is as shown Table 1 . Inclusion criteria

Randomised controlled trials (RCTS)

Non-randomised controlled trials, cohort studies and other studies

Double blinded RCTs on the treatment of uncomplicated malaria in

under fives

Single blinded or no blinding studies on the treatment of uncomplicated malaria in under fives

All studies must have less than $15 \%$ drop out rate

Inconsistencies in the dropout rate in each study [22] [23]

NB: the method of randomizing subjects and form of blinding played a major role in the inclusion criteria [24]. In appraising the inclusion criteria for the study, the Cochrane's tool for assessing bias was used [25]. The rationale for this is because studies assessed with this tool reports low risks of bias [16] [26]. 


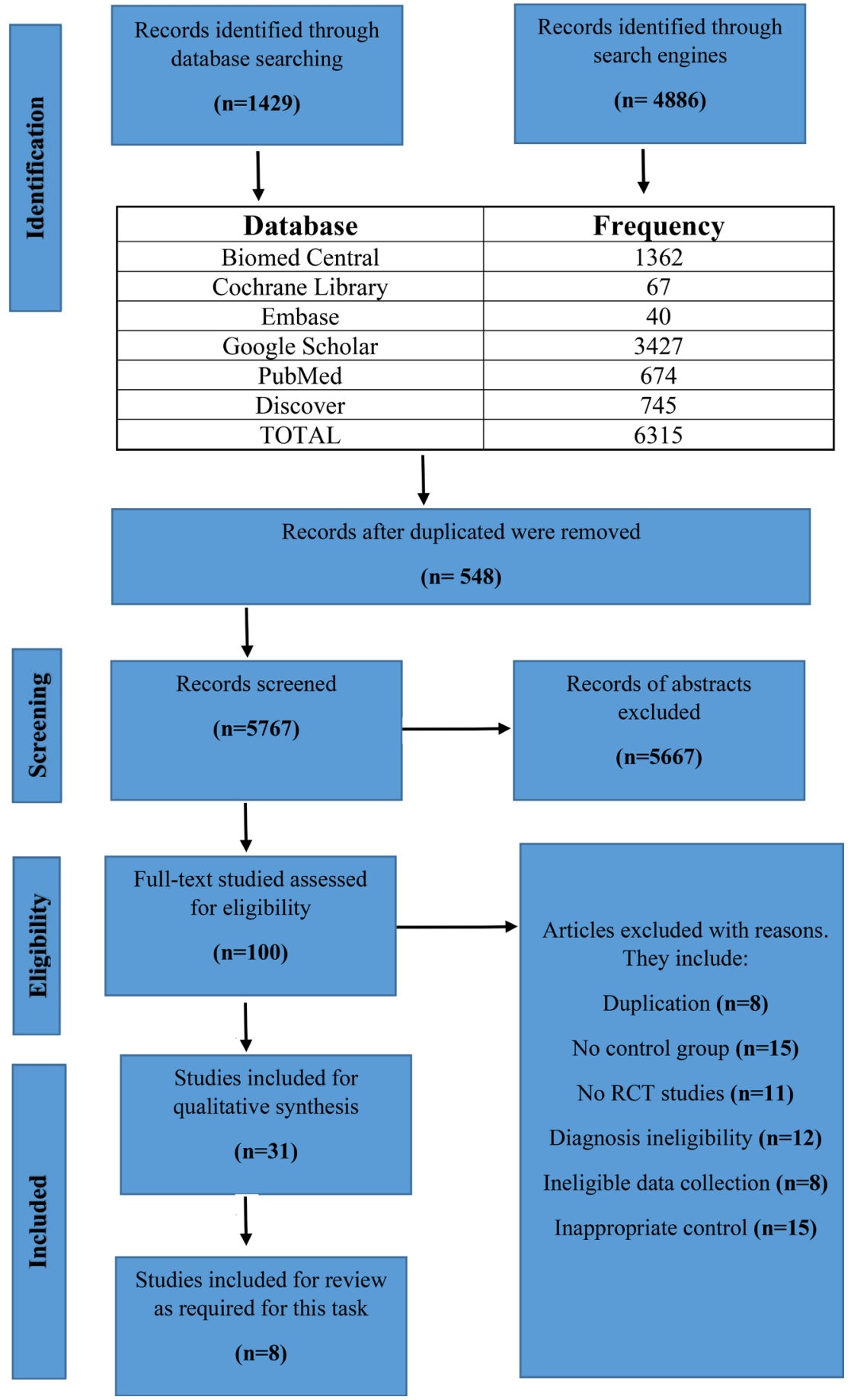

Figure 2. PRISMA flow diagram for the included studies.

\subsection{Characteristics of Included Studies}

A total of 8 studies from 31 full-text studies were included in this review. The total numbers of participants in this review were 10,682 with an average of 1335 participants per study. However, the study with the highest number of participants had 4116 participants [32] while the least number of participants were 218 participants [33]. The age distributions of participants across the studies were 0 - 
Table 2. Showing characteristics of included studies.

\begin{tabular}{|c|c|c|c|c|c|c|c|c|c|c|c|c|}
\hline $\begin{array}{l}\text { Study ID } \\
\text { and year }\end{array}$ & $\begin{array}{l}\text { Sample } \\
(\mathrm{M} / \mathrm{F})\end{array}$ & $\begin{array}{l}\text { Diagnostic } \\
\text { Standard }\end{array}$ & \multicolumn{4}{|c|}{ Intervention } & \multicolumn{4}{|c|}{ Control } & $\begin{array}{l}\text { Course } \\
\text { (Weeks) }\end{array}$ & $\begin{array}{l}\text { Outcome } \\
\text { measured }\end{array}$ \\
\hline $\begin{array}{l}\text { Faye } \\
\text { et al. } \\
(2010)\end{array}$ & 320 & $\begin{array}{c}10-20 \mathrm{~kg}, \mathrm{MCP} \\
(2000-100,000 \mu \mathrm{L}) \\
\text { Fever }\left(\geq 37.5^{\circ} \mathrm{C}\right)\end{array}$ & \multicolumn{4}{|c|}{ Artesunate + Mefloquine (AS + MQ) } & \multicolumn{4}{|c|}{ Arthemether- Lumefantrine (AL) } & 4 & $\begin{array}{l}\text { Malaria } \\
\text { treatment }\end{array}$ \\
\hline $\begin{array}{l}\text { Kapisi } \\
\text { et al. } \\
(2015)\end{array}$ & $\begin{array}{c}3113 \\
(1723 / 1370)\end{array}$ & $\begin{array}{l}\text { Blood conformation } \\
\text { of Parasitaemia }\end{array}$ & \multicolumn{4}{|c|}{$\begin{array}{l}\text { Monthly Sylphadoxine- } \\
\text { Pyrimethamine (SP) }\end{array}$} & \multicolumn{4}{|c|}{$\begin{array}{c}\text { Monthly } \\
\text { Dihydroartemisinin- } \\
\text { Piperaquine (DHAPQ) }\end{array}$} & 4 & $\begin{array}{l}\text { Malaria } \\
\text { treatment }\end{array}$ \\
\hline $\begin{array}{l}\text { Maiga et al. } \\
\quad \text { (2015) }\end{array}$ & $\begin{array}{c}912 \\
(470 / 442)\end{array}$ & $\begin{array}{c}>5 \mathrm{~kg}, \mathrm{MCP}(2000- \\
100,000 \mu \mathrm{L}), \text { Fever } \\
\left(\geq 37.5^{\circ} \mathrm{C}\right), \mathrm{Hb}(7.0 \\
\mathrm{g} / \mathrm{dl})\end{array}$ & \multicolumn{3}{|c|}{$\begin{array}{c}\text { Sulphadoxine-Pyrimethamine + } \\
\text { Artesunate }(\mathrm{SP}+\mathrm{AS})\end{array}$} & \multicolumn{2}{|c|}{$\begin{array}{l}\text { Sulphadoxine-Pyrimethamine }+ \\
\text { Amodiaquine }(\mathrm{SP}+\mathrm{AQ})\end{array}$} & \multicolumn{3}{|c|}{$\begin{array}{c}\text { Sulphadoxine-Pyrimethamine (SP) } \\
\text { Monotherapy }\end{array}$} & 4 & $\begin{array}{l}\text { Malaria } \\
\text { treatment }\end{array}$ \\
\hline $\begin{array}{l}\text { Nambozi } \\
\text { et al. } \\
(2011)\end{array}$ & $\begin{array}{c}304 \\
(176 / 128)\end{array}$ & $\begin{array}{c}>5 \mathrm{~kg}, \mathrm{MCP}(2000- \\
200,000 \mu \mathrm{L}), \text { Fever } \\
\left(\geq 37.5^{\circ} \mathrm{C}\right)\end{array}$ & \multicolumn{4}{|c|}{ Dihydroartemisinin-Piperaquine (DHAPQ) } & \multicolumn{4}{|c|}{ Arthemether-Lumefantrine (AL) } & 6 & $\begin{array}{l}\text { Malaria } \\
\text { treatment }\end{array}$ \\
\hline $\begin{array}{c}\text { The } 4 \mathrm{ABC} \\
\text { study } \\
\text { Group } \\
(2011)\end{array}$ & $\begin{array}{c}4116 \\
(2179 / 1897)\end{array}$ & $\begin{array}{c}>5 \mathrm{~kg}, \mathrm{MCP}(2000- \\
100,000 \mu \mathrm{L}), \text { Fever } \\
\left(\geq 37.5^{\circ} \mathrm{C}\right), \mathrm{Hb}(7.0 \\
\mathrm{g} / \mathrm{dl})\end{array}$ & Artesunate $+A$ & Amodiaquine ( & $(A S+A Q)$ & $\begin{array}{r}\text { Dihydroar } \\
\text { Piperaquine }\end{array}$ & \multicolumn{4}{|c|}{$\begin{array}{l}\text { Chlorproguanil-dapsone + } \\
\text { Artesunate }(\mathrm{CD}+\mathrm{A})\end{array}$} & 4 & $\begin{array}{l}\text { Malaria } \\
\text { treatment }\end{array}$ \\
\hline $\begin{array}{l}\text { Whegang } \\
\text { et al. } \\
(2010)\end{array}$ & 1401 & $\begin{array}{c}>5 \mathrm{~kg}, \mathrm{MCP}(2000- \\
100,000 \mu \mathrm{L}), \text { Fever } \\
\left(\geq 37.5^{\circ} \mathrm{C}\right)\end{array}$ & $\begin{array}{l}\text { Amodiaquine } \\
\text { Monotherapy } \\
\text { (AQ) }\end{array}$ & $\begin{array}{l}\text { Artesunate } \\
\text { amodiaquine } \\
(\mathrm{AS}+\mathrm{AQ})\end{array}$ & $\begin{array}{l}\text { Sulphadoxine- } \\
\text { Pyrimethamine } \\
\text { (SP) }\end{array}$ & $\begin{array}{c}\text { Sulphadoxin } \\
\text { e-Pyrimetha } \\
\text { mine }+ \\
\text { Amodiaquin } \\
\text { e (SP+AQ) }\end{array}$ & $\begin{array}{l}\text { Chlorproguanil } \\
\text {-dapsone } \\
\text { +Artesunate } \\
\text { (CD + A) }\end{array}$ & $\begin{array}{l}\text { Artesunate- } \\
\text { mefloquine } \\
\text { (AS-MQ }\end{array}$ & $\begin{array}{l}\text { Artemether- } \\
\text { lumefantrine } \\
\text { (AL) }\end{array}$ & $\begin{array}{c}\text { Dihydroarte } \\
\text { misinin-piper } \\
\text { aquine } \\
\text { (DHAPQ) }\end{array}$ & 4 & $\begin{array}{l}\text { Malaria } \\
\text { treatment }\end{array}$ \\
\hline $\begin{array}{l}\text { Yeka et al. } \\
\quad(2013)\end{array}$ & $\begin{array}{c}218 \\
(127 / 91)\end{array}$ & $\begin{array}{c}>5 \mathrm{~kg}, \mathrm{MCP} \\
(2000-100,000 \mu \mathrm{L}) \\
\text { Fever }\left(\geq 37.5^{\circ} \mathrm{C}\right)\end{array}$ & \multicolumn{4}{|c|}{ Quinine (Q) } & \multicolumn{4}{|c|}{ Arthemether-Lumefantrine (AL) } & 4 & $\begin{array}{l}\text { Malaria } \\
\text { treatment }\end{array}$ \\
\hline
\end{tabular}

N. B: $\mathrm{MCP}=$ Microscopically confirmed plasmodiasis; $\mathrm{Hb}=$ Haemoglobin

59 months. All studies had similar specific diagnostic criteria which was "Microscopically confirmed plasmodiasis" in patients within the age range. Also, all studies except Kapisi and colleagues [34] excluded other participants with other conditions like HIV. HIV exposure is not a complication of malaria neither is malaria a complication of HIV hence the study was included in this study. A brief description of the characteristics of the included study includes: Artesunate + Mefloquine versus Arthemeter-Lumefantrine [35]; No chemoprevention versus Sulphadoxine-Pyrimethamine versus Trimethoprim-Sulphamethoxazole versus Dihydroartemisin-Piperaquine [34]; Sulphadoxine-Pyrimethamine + Artesunate versus Sulphadoxine-Pyrimethamine + Amodiaquine versus Sulphadoxine-Pyrimethamine [36], Dihydroartemisin-Piperaquine versus Artemether-Lumefantrine [37]; Artesunate + Amodiaquine versus Artemether-Lumefantrine [38] and Artesunate + Amodiaquine versus Dihydroartemisin-Piperaquine versus Arthemeter-Lumefantrine versus Chroproguanil-daspone + Amodiaquine [32]. Other studies in this review include Amodiaquine versus Sulphadoxine-Pyrimethamine versus Sulphadoxine-Pyrimethamine + Amodiaquine [39]; and Quinine versus Arthemeter-Lumefantrine versus Dihydroartemisin-Piperaquine [33]. The studies were carried in a total of 3 - 6 weeks. Majority of the studies (75\%) were carried out in 4 weeks while 2 studies (25\%) were carried out in 6 weeks. Hence the average number of weeks of study is 4.5 weeks. The total number of medications (anti- 
malarial) in this review is 13 . The study with the highest number of antimalarial per study was 12 medications [39] while Faye et al. [35], Nambozi et al. [37] and Schramm et al. [38] had 2 medications each to account for studies with lowest number of medications per study. On the average, a total of 3.5 medications were used per study. See characteristics of included study table (Table 2).

\subsection{Quality of Included Studies (Risk of Bias)}

The Cochrane's tool for assessing bias was used to determine the quality of the included studies [25] the quality of the included studies generally was high except in the areas of blinding of outcome of assessment with $40 \%$ high risk of bias as reported in Table 3, Figure 3 and Figure 4 respectively. Graphical and tabular representations of the quality of the included studies are displayed on Figure 3, Figure 4 and Table 2. All studies randomised the participants in their study. Similarly, all included studies (100\%) used random sequencing generation in allocating participants into various study groups however, $75 \%$ of the studies concealed their random sequencing generation while $25 \%$ were unclear about their allocation concealment [32] [34]. Therefore, for studies with unclear allocation concealment, there was insufficient knowledge to ascertain if they were or were not conducted properly (Figure 3 and Figure 4). In the aspect of blinding of participants, only 2 studies (25\%) Maiga et al. [36] Schramm et al. [38] used blinding technique for their participants. Thus $50 \%$ and $25 \%$ had unclear risks and high risk of bias respectively.

According to Higgins and Green [14], different types of people can be blinded in the course of conducting a study. Poor blinding of participants and/or healthcare providers introduces bias which may affect the end point (result) of the study. However, there are studies which describe the type of randomisation in a "blind" or "double-blinded" of either or both participants and personnel.

Table 3. Showing quality of included studies.

\begin{tabular}{|c|c|c|c|c|c|c|c|}
\hline Study ID and Year & $\begin{array}{l}\text { Random } \\
\text { Sequencing } \\
\text { Generation }\end{array}$ & $\begin{array}{l}\text { Allocation of } \\
\text { concealment }\end{array}$ & $\begin{array}{l}\text { Blinding of } \\
\text { participants }\end{array}$ & $\begin{array}{l}\text { Blinding of } \\
\text { outcome } \\
\text { assessment }\end{array}$ & $\begin{array}{c}\text { Incomplete } \\
\text { Outcome Data }\end{array}$ & $\begin{array}{l}\text { Selective } \\
\text { Reporting }\end{array}$ & Other Bias \\
\hline Faye et al. (2010) & + & + & $?$ & $?$ & + & + & + \\
\hline Kapisi et al. (2015) & + & $?$ & $?$ & - & + & + & - \\
\hline Maiga et al. (2015) & + & + & + & + & + & $?$ & + \\
\hline Nambozi et al. (2011) & + & + & - & + & + & + & + \\
\hline Schramm et al. (2013) & + & + & + & + & + & + & + \\
\hline The 4ABC study Group (2011) & + & $?$ & $?$ & $?$ & + & + & + \\
\hline Whegang et al. (2010) & + & + & $?$ & $?$ & + & - & + \\
\hline Yeka et al. (2013) & + & + & - & - & + & $?$ & + \\
\hline
\end{tabular}




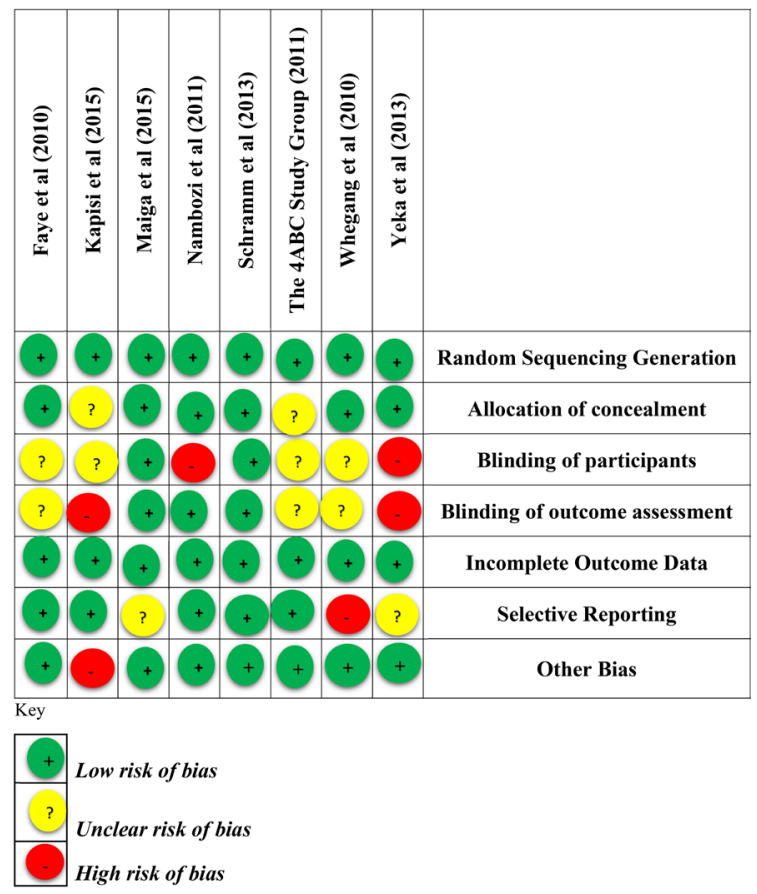

Figure 3. Showing risk of bias summary; review of authors' judgement about each risk of bias.

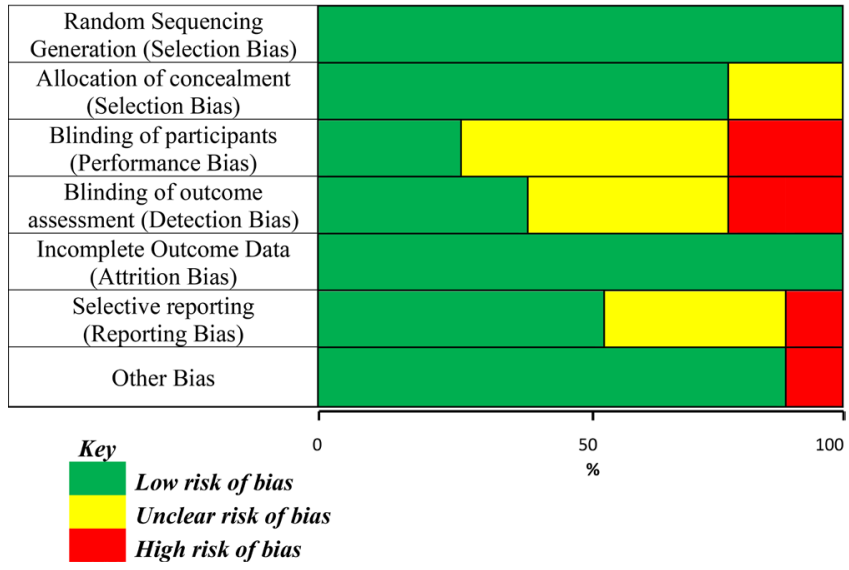

Figure 4. Showing risk of bias summary; review of authors' judgement about each item presented in percentage across all included studies.

Yet in empirical studies, poor blinding exaggerates estimated intervention by $9 \%$ when measured on odds ratio. Hence the RCTs in this review reveal both subjective and objective outcomes (plasmodium clearance and elimination of fever after treatment).

Blinding of outcome assessment in this study occurred in 3 studies (38\%) [36] [37] [38] while $38 \%$ and $25 \%$ were unclear and had high risk bias respectively. Often times, when outcomes are made known, subjective data are difficult to obtain as such data seeks to favour the study's expected outcome. All studies (100\%) stated the number of participants and analysed the number that was present for follow-up. Conversely, all studies had few numbers of dropouts 
(missing data due to attrition). In all cases of missing data, either death or absence of participants and their parents/guidance were the cause of attrition [39] [40] [41]. It is important to note that concerns over bias from incomplete data are often left for theoretical considerations. Previous studies on the relationship between missing data and the magnitude of effects of potential bias found that there is no clear evidence of bias [42] [43]. Furthermore, 5 studies (63\%) did not employ selective reporting while analysing their studies. However, 2 studies had unclear risk of bias, as one study had a high risk of bias for selective reporting [33]. Other forms of bias seen in this study was in one study (12\%) [34]. While other studies showed no sign of other bias. These combine to present a high methodology for the included studies as seen on Figure 3, Figure 4 and Table 4.

The inclusion of the studies was determined by their quality as seen on Table 3.

\subsection{Review of Findings from Included Studies}

According to The 4ABC Study Group (2011), the efficacy can be summarised as Arthemeter-Lumefantrine versus Dihydroartemisin-Piperaquine (95.5\% vs $97.3 \%$ ); Artesunate + Amodiaquine versus Dihydroartemisin-Piperaquine (96.8\% vs 97.6\%) and Arthemeter-Lumefantrine vs Artesunate + Amodiaquine (94.4\% vs $97.1 \%)$. On the $28^{\text {th }}$ day of trial, Arthemeter-Lumefantrine was notably less efficacious than Dihydroartemisin-Piperaquine and Artesunate + Amodiaquine. Also, the three medications were more effective than Chroproguanil-daspone + Amodiaquineas reported on Table 4. Although a closer look at individual sites, Dihydroartemisin-Piperaquine when compared with Arthemeter-Lumefantrine was higher in the three sites. Parasite clearance was rapid in all treatment groups as majority of patients had no signs and symptom of infection at Day 3. At baseline, 60\% had fever. Consequently, on Day 3, 95\% participants were afebrile. Similarly, there was increased $\mathrm{Hb}$ in all groups at Day 0 which later returned to the level at baseline (Day 0) at Day 7 with the exception of patient treated with Chroproguanil-daspone + Amodiaquine. There was no significant difference in Arthemeter-Lumefantrine, Artesunate + Amodiaquine and Dihydroartemisin-Piperaquine treatment groups. However, there was rapid clearance of parasites and fever in the study comparing Artesunate $+\mathrm{Me}$ floquine and Arthemeter-Lumefantrine in Faye et al. (2010) [35]. Complete parasite clearance on Day 2 in $97.5 \%$ and $98.1 \%$ respectively. The complete treatment of fever occurred in $79 \%$ and $80 \%$ after the first dose. Also, after 48 hours, complete parasite clearance was $99 \%$ in both groups. Gametocyte clearance was $5.8 \%$ in the Artesunate + Mefloquine versus 3.9\% in Arthemeter-Lumefantrine group which reduced to $2.5 \%$ and $1 \%$ respectively on Day 7 and no traces on Day 14 . Hb level was lower at Day 7 in both groups but was not notable. However, anaemia was common in Arthemeter-Lumefantrine group on Day 7 (73.7\% versus 65.6\%) as in Artesunate + Mefloquine group $(\mathrm{P}<0.001)$ (Faye et al. 2010) [35].

Maiga et al. [36] found 294 (1.4\%) early treatment failures in the Sulphadoxine- 
Table 4. Showing summary of the findings from included studies.

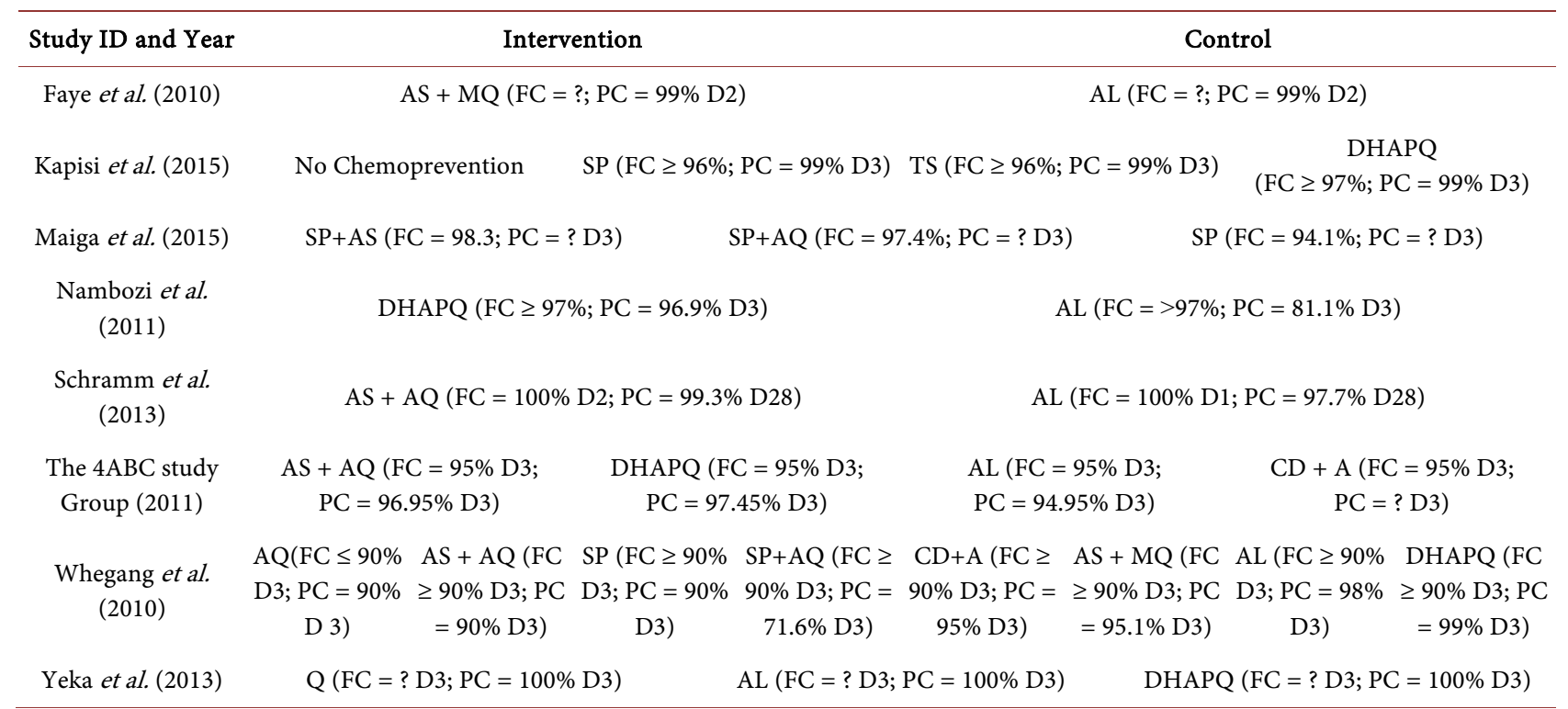

$\mathrm{NB}: \mathrm{AS}+\mathrm{MQ}=$ Artesunate + Mefloquine; $\mathrm{AL}=$ Arthemether-Lumefantrine; $\mathrm{SP}=$ Sulphadoxine-Pyrimethamine; $\mathrm{TS}=$ trimethoprim-Sulphamethoxazole; $\mathrm{DHAPQ}=$ Dihydroartemisinin-Piperaquine; $\mathrm{SP}+\mathrm{AS}=$ Sulphadoxine-Pyrimethamine + Artesunate; $\mathrm{SP}+\mathrm{AQ}=$ Sulphadoxine-Pyrimethamine + Amodiaquine; $\mathrm{AS}+\mathrm{AQ}=$ Artesunate + Amodiaquine; $\mathrm{CD}+\mathrm{A}=$ Chlorproguanil-dapsone + Artesunate; $\mathrm{AQ}=$ Amodiaquine; $\mathrm{Q}=\mathrm{Quinine}$. $\mathrm{FC}=\mathrm{Fever}$ Clearance rate in \%; $\mathrm{PC}=$ Parasite Clearance in \%; $\mathrm{D}=$ Day of trial. ? = unknown result.

Pyrimethamine monotherapy group and none in Sulphadoxine-Pyrimethamine + Artesunate and Sulphadoxine-Pyrimethamine + Amodiaquine groups. There was rapid reduction in fever in all groups as $1.7 \%, 2.6 \%$ and $5.9 \%$ of Sulphadoxine-Pyrimethamine + Artesunate, Sulphadoxine-Pyrimethamine + Amodiaquine and SP treatment groups had the parasite on Day 3. Gametocyte carriage decreased between baseline and on Day 28 in Sulphadoxine-Pyrimethamine + Artesunate and Sulphadoxine-Pyrimethamine + Amodiaquine with no decrease found in the SP treatment monotherapy group. On Day 28, there was no reduction in the prevalence of malaria in all the groups. Hence the non-ACTs like Sulphadoxine-Pyrimethamine + Amodiaquine was as efficacious as Artemisinin-based combination of Sulphadoxine-Pyrimethamine + Artesunate. Schramm et al. (2013) result showed that the Day 42 genotyping-adjusted cure rate of Sulphadoxine-Pyrimethamine + Amodiaquine and Arthemeter-Lume- fantrine was 97.3\% (95\% CI: 91.6 - 99.1) and 94.2\% (95\% CI, 88.1\% - 97.2\%) respectively whereas Day 28 genotyping-adjusted cure rate estimate were $99.3 \%$ and $97.3 \%$ with $95 \%$ CI at 95.1 - 99.9 and 93.6 - 99.3 in Sulphadoxine-Pyrimethamine + Amodiaquine and Arthemeter-Lumefantrine treatment groups respectively. Patients with no gametocytes at baseline had a peak on Day 2 and reduced to $0.9 \%$ and $0 \%$ on Day 28 in Sulphadoxine-Pyrimethamine + Amodiaquine and Arthemeter-Lumefantrine groups. Fever clearance was $100 \%$ on Day 1 in Arthemeter-Lumefantrine group and 98\% and 100\% respectively on Day 1 and 2 in Artesunate + Amodiaquine group respectively.

Alternatively, in the study involving Sulphadoxine-Pyrimethamine + Amodiaquine, Amodiaquine, Sulphadoxine-Pyrimethamine, Sulphadoxine-Pyrimethamine + Amo- 
diaquine, Chroproguanil-daspone + Amodiaquine, Artesunate + Mefloquine, Arthemeter-Lumefantrine and Dihydroartemisin-Piperaquine showed that the cure rate of Artesunate + Amodiaquine with adequate clinical and parasitological response (ACPR) of $93.0 \%$ on Day 14 and $78 \%$ before PCR correction and 91\% after PCR correction. There was no change in effectiveness in Amodiaquine monotherapy $(1.61,95 \% \mathrm{CI}=0.6$ - 4.54) on Day 14, Sulphadoxine-Pyrimethamine was less effective than Sulphadoxine-Pyrimethamine + Amodiaquine with cure rate of $87 \%$ ( $95 \mathrm{CI}=0.82-0.92)$. Hence, the efficiency of the three medications after ITT analysis was $78.1 \%, 71.6 \%$ and $82 \%$ (ACPR) and $86 \%, 88.3 \%$ and $98.3 \%$ of Amodiaquine, Sulphadoxine-Pyrimethamine and Sulphadoxine-Pyrimethamine + Amodiaquine respectively after PCR correction. Furthermore, PCR correction was $88.7 \%$ and $98.3 \%$ in Artesunate + Amodiaquine and Arthemeter-Lumefantrine groups on Day 28. Artesunate + Amodiaquine was less effective than DHAPQ (79.3\% and 92.3\%). Parasite clearance was higher in Dihydroartemisin-Piperaquine than Artesunate + Amodiaquine $(\mathrm{P}<-0.05)$. Using ITT analysis on, Sulphadoxine-Pyrimethamine + Amodiaquine (63\%) was less effective than Chroproguanil-daspone + Amodiaquine (85.9\%). However, on Day 28 effectiveness was 91.7\% and $76 \%$ respectively. Parasite clearance was more in Artesunate + Mefloquine than Sulphadoxine-Pyrimethamine + Amodiaquine on Day 2 with similar difference on Day 3 (95.7\% vs $86.6 \%$ ). 90\% of participants were cleared of parasitaemia on Day 3 except Sulphadoxine-Pyrimethamine + Amodiaquine and Amodiaquine monotherapy [39].

Yeka et al. [33] study revealed 70\%, 60\% and 25\% recurrent malaria in Quinine, Arthemeter-Lumefantrine and Dihydroartemisin-Piperaquine treatment groups although. Quinine and Arthemeter-Lumefantrine had significant higher risk of recurrent infection than Dihydroartemisin-Piperaquine with 95\% CI 1.23 (0.78 - 2.00), $3.98(2.37$ - 6.68) and $3.32(1.76$ - 6.26) for Quinine versus Arthemeter-Lumefantrine, Quinine versus Dihydroartemisin-Piperaquine and Arthemeter-Lumefantrine versus Dihydroartemisin-Piperaquine respectively. Parasite clearance was eliminated on Day 3 in all groups. The Haemoglobin $(\mathrm{Hb})$ level indicative of anaemia was observed to be between $24.3 \%$ - 9.8\% (Quinine), 25.7\% - 9.8\% (Arthemeter-Lumefantrine), and 18.3\% - 6.1\% (Dihydroartemisin-Piperaquine) on day 28 of treatment. No gametocyte was observed at enrolment or follow-up. However, at Day 28 in Nambozi et al. [37], the percentage of participants with recurrent infection was lower than the comparing Dihydroartemisin-Piperaquine and Arthemeter-Lumefantrine (7.8\% and 25.6\%). Most recurrent infections reported were due to new infections (3.1\% in Dihydroartemisin-Piperaquine and $18.9 \%$ in Arthemeter-Lumefantrine). Parasite clearance in both groups on the onset of the treatment was $60 \%$ with fever while $97 \%$ of participants were afebrile on day 2 of treatment with gametocyte clearance of $11.75 \%$ and $12.94 \%$ respectively. Upon completion of the study, gametocyte carriage measure rate was higher in Dihydroartemisin-Piperaquine than Arthemeter-Lumefantrine group (43/1000 and 21.43/1000). No recurrent para- 
sitaemia was observed thus resulting in increased $\mathrm{Hb}$ at day $28(+1.39 \mathrm{~g} / \mathrm{dL}$ in Dihydroartemisin-Piperaquine and $+0.89 \mathrm{~g} / \mathrm{dL}$ in Arthemeter-Lumefantrine). Early response to treatment was observed in Arthemeter-Lumefantrine across all groups in Kapisi et al. [34] and no notable difference across the chemoprevention groups with over $96 \%$ participants being afebrile at day 3. Parasite clearance was also similar across the chemoprevention groups of Sulphadoxine-Pyrimethamine, Trimethoprim-Sulphamethoxazole and Dihydroartemisin-Piperaquine with 92\% and $99 \%$ negative blood smear on day 2 and 3 respectively. The findings revealed that 16 participants had early treatment failures while 14 developed signs of severe malaria within 2 days of Arthemeter-Lumefantrine administration with positive blood smear and persistent fever on day 3 of treatment while $43.5 \%$ of participants developed recurrent parasitaemia within 28 days of follow-up. There was no difference however, in the appearance of gametocytes and $\mathrm{Hb}$ across Chemoprevention groups. It is pertinent to note that when follow-up was extended to 84 days, after treating with Arthemeter-Lumefantrine, recurrent malaria rose to $72.2 \%$ in Dihydroartemisin-Piperaquine and $81.0 \%$ in no chemoprevention group and $23 \%$ reduction in $95 \%$ CI compared to no chemoprevention 0.63 - 0.95. No notable difference was observed in Sulphadoxine-Pyrimethamine and Trimethoprim-Sulphamethoxazole chemoprevention [34].

\subsection{Adverse Events (Complications from the Study)}

All studies reported adverse events. Most of the adverse events were related to the prognosis of the severity of malaria especially in studies that reported death of participants [32], however, finding was not stated in Sulphadoxine-Pyrimethamine group [36]. Faye et al. (2010) assert that there was report of vomiting in $30 \%$ and $36 \%$ of participants treated with Artesunate + Mefloquine and Arthemeter-Lumefantrine groups. Whegang et al. [39] reported treatment failure in 5\% of Artesunate + Mefloquine on Day 28, 29 and 42. In Nambozi et al. [37] study, three participants were excluded due to repeated vomiting with 7 serious adverse events and three with prolonged hospitalization (Dihydroartemisin-Piperaquine $=2$ and Arthemeter-Lumefantrine $=1$ ). Low risk of diarrhoea and vomiting in Sulphadoxine-Pyrimethamine monotherapy group was observed. There was however, report of cough and diarrhoea in the Trimethoprim-Sulphamethoxazole monotherapy group and finally only diarrhoea in DihydroartemisinPiperaquine group (Kapisi et al. 2015).

\section{Discussion}

This study analysed 8 RCTs on the treatment of uncomplicated malaria in under 5 children. The studies involved a total of 10,682 participants with an average of 1335 participants per study. The study used different pharmaceutical antimalarial agents approved for the treatment of malaria in humans. All studies had similar study objectives, baseline demographic characteristics and study popula- 
tion but different antimalarial agents.

Two common objectives among the studies were: reduction of fever and parasite clearance. According to the findings, all antimalarial in this study were effective in reducing fever parasite clearance. Although Arthemeter-Lumefantrine was often the drug of choice, it was not the only medication found to be effective from analysis. Artesunate + Amodiaquine and Dihydroartemisin-Piperaquine were also effective in the early reduction of fever and parasite clearance. Based on these findings, it is important to note that the use of single antimalarial monotherapy (Quinine, Amodiaquine and Sulphadoxine-Pyrimethamine) had records of failures compared to antimalarial combination therapies. Previously, monotherapy had been effective in the treatment of uncomplicated malaria until there was report of resistance to antimalarial monotherapy medications. Sodahlon and colleagues [44] study report supported this assertion on the low quality in the efficacy of Quinine and Amodiaquine in children whose indication has been diminished with the production of Arthemeter-Lumefantrine, Artesunate + Amodiaquine and other antimalarial combination therapies [45]. From the analysis, Artesunate + Amodiaquine showed faster fever clearance than AL due to the antipyretic properties of Artesunate. This is in agreement with studies by Gbotosho et al. [46] [47] which state that Artesunate + Amodiaquine has antipyretic properties that act in fever clearance thus their high recommendation for its use in the treatment of uncomplicated Malaria especially among under $5 \mathrm{~s}$. This evidence is supported by the approval of Arthemeter-Lumefantrine as the first line drug of choice in the treatment of malaria by WHO [48] in Africa. The findings also revealed that fever elimination was quicker in children treated with Artesunate + Amodiaquine and Arthemeter-Lumefantrine than other antimalarial as reported by Oguche and colleagues [49] study.

This review observed that both ACTs and Non-ACTs use resulted in the elimination of the malaria parasites by the spleen. This is in agreement with Chotwanich et al. [50] and Gbotosho et al. [51] studies who opined that antimalarial combination therapies eliminate parasites more than monotherapies. It also observed that there was haemoglobin improvement to a normal level after the treatment with the above drugs of choice. Anaemia due to destruction red blood cells was thus significantly reduced after treatment compared with baseline level prior to the commencement of the trials. This finding was supported by Oguche and colleagues [49] study stating that effective use of antimalarial results in improvement of haemoglobin. The analysis showed that reduction in haemoglobin level from the use of AL, Artesunate + Amodiaquine and Dihydroartemisin-Piperaquine were faster compared with other antimalarial. Nevertheless, the disparities of the adverse events reported in the studies were not different from the signs and symptoms of uncomplicated malaria thus the result of withdrawal from the studies by participants were minimal as all studies had under $15 \%$ withdrawal rate. Although differentiating the side effects from signs and symptoms of uncomplicated malaria is difficult, measuring the severity can be de- 
termined through prolonged/resistance to treatment. Studies involving Arthemeter-Lumefantrine, Artesunate + Amodiaquine and Dihydroartemisin-Piperaquine, reported participants' tolerance of these drugs more than other drugs may be due to the high fever and parasite clearance. Studies suggest that compliance and tolerance to antimalarial agents results in increased efficacy in the treatment of uncomplicated malaria in children [52] [53].

\section{Conclusion}

This study systematically reviewed studies involving different antimalarial used in the treatment of uncomplicated malaria under $5 \mathrm{~s}$ children. A total of 8 RCTs were reviewed with above average low risk bias in qualities of studies. The rate of low risk of bias was high among the studies used thus considering this study to be of high quality. Findings showed that Arthemeter-Lumefantrine, Artesunate + Amodiaquine and Dihydroartemisin-Piperaquine were best drugs of choice due to their fast fever rate reduction and parasite clearance. No difference was observed in the efficacy of Arthemeter-Lumefantrine when compared to $\mathrm{Ar}$ tesunate + Amodiaquine and Dihydroartemisin-Piperaquine in the treatment of uncomplicated malaria. It is suggested that due to the faster rate of fever reduction in participants when treated with Artesunate + Amodiaquine and Dihydroartemisin-Piperaquine, there is need to classify Arthemeter-Lumefantrine, Artesunate + Amodiaquine and Dihydroartemisin-Piperaquine among the first line drugs in the treatment of uncomplicated and resistant malaria respectively.

\section{Conflicts of Interest}

The authors declare no conflicts of interest regarding the publication of this paper.

\section{References}

[1] WHO (2010) World Malaria Report 2010. WHO, Geneva. https://www.who.int/malaria/world malaria report 2010

[2] WHO (2013) Implementation of General Assembly Resolution 66/289 on Consolidating Gains and Accelerating Efforts to Control and Eliminate Malaria in Developing Countries, Particularly in Africa, by 2015. Report of the Director General of the World Health Organization.

[3] The Federal Ministry of Health (2012) Roll Back Malaria Partnership: Progress and Impact Series. Country Reports, Number 4, April 2012.

[4] WHO (2012) World Health Statistics 2012: Indicator Compendium. WHO, Geneva.

[5] National Population Commission (2009) Nigeria Demographic and Health Survey 2008. Abuja

[6] Nubé, M. and Sonneveld, B.G. (2005) The Geographical Distribution of Underweight Children in Africa. Bulletin of the World Health Organization, 83, 764-770.

[7] WHO (2009) Global Estimates of Malaria Cases and Deaths in 2008. World Malaria Report: 27.

[8] Rezai, M.S., Enayati, A. and Heamingway, J. (2013) Malaria in Children, Prospects 
and Challenges. Journal of Pediatrics Review, 1, 19-24.

[9] Plucinski, M.M., Talundzic, E., Morton, L., Dimbu, P.R., Macaia, A.P., Fortes, F., Udhayakumar, V., et al. (2015) Efficacy of Artemether-Lumefantrine and Dihydroartemisinin-Piperaquine for Treatment of Uncomplicated Malaria in Children in Zaire and Uíge Provinces, Angola. Antimicrobial Agents and Chemotherapy, 59, 437-443. https://doi.org/10.1128/AAC.04181-14

[10] Dahlström, S., Aubouy, A., Maïga-Ascofaré, O., Faucher, J.F., Wakpo, A., Ezinmègnon, S., Houzé, S., et al. (2014) Plasmodium falciparum Polymorphisms Associated with ex Vivo Drug Susceptibility and Clinical Effectiveness of Artemisinin-Based Combination Therapies in Benin. Antimicrobial Agents and Chemotherapy, 58, 1-10. https://doi.org/10.1128/AAC.01790-12

[11] WHO (2014) Malaria: From Malaria Control to Malaria Elimination: A Manual for Elimination Scenario Planning April 2014.

http://www.who.int/malaria/publications/atoz/9789241507028/en

[12] Crowther, M., Lim, W. and Crowther, M.A. (2010) Systematic Review and Meta-Analysis Methodology. Blood, 116, 3140-3146.

https://doi.org/10.1182/blood-2010-05-280883

[13] Higgins, J.P., Altman, D.G., Gøtzsche, P.C., Jüni, P., Moher, D., Oxman, A.D., Sterne, J.A., et al. (2011) The Cochrane Collaboration's Tool for Assessing Risk of Bias in Randomised Trials. British Medical Journal, 343, 5928-5931.

https://doi.org/10.1136/bmj.d5928

[14] Higgins, J.P. and Green, S. (2008) Cochrane Handbook for Systematic Reviews of Interventions. John Wiley \& Sons, Chichester.

https://doi.org/10.1002/9780470712184

[15] Moher, D., Hopewell, S., Schulz, K.F., Montori, V., Gøtzsche, P.C., Devereaux, P.J., Altman, D.G., et al. (2010) CONSORT 2010 Explanation and Elaboration: Updated Guidelines for Reporting Parallel Group Randomised Trials. Journal of Clinical Epidemiology, 63, 1-37. https://doi.org/10.1016/j.jclinepi.2010.03.004

[16] Higgins, J., Ramsay, C., Reeves, B. C., Deeks, J.J., Shea, B., Valentine, J.C., Wells, G., et al. (2013) Issues Relating to Study Design and Risk of Bias When Including Non-Randomized Studies in Systematic Reviews on the Effects of Interventions. Research Synthesis Methods, 4, 12-25. https://doi.org/10.1002/jrsm.1056

[17] Nazroo, J.Y. (2006) Health and Social Research in Multiethnic Societies. Routledge, New York. https://doi.org/10.4324/9780203969939

[18] Lown, C., Sierra, T. and Boyer, J. (2013) How Users Search the Library from a Single Search Box. College \& Research Libraries, 74, 227-241.

https://doi.org/10.5860/crl-321

[19] Yang, S.Q. and Hofmann, M.A. (2013) The Next Generation Library Catalog: A Comparative Study of the OPACs of Koha, Evergreen, and Voyager. Information Technology and Libraries, 29, 141-150. https://doi.org/10.6017/ital.v29i3.3139

[20] Kristjansson, E., Francis, D.K., Liberato, S., Benkhalti Jandu, M., Welch, V., Batal, M., Petticrew, M., et al. (2012) Feeding Interventions for Improving the Physical and Psychosocial Health of Disadvantaged Children Aged Three Months to Five Years. Cochrane Database of Systematic Reviews, No. 6, CD009924. https://doi.org/10.1002/14651858.CD009924

[21] Higgins, J.P. (2008) Cochrane Handbook for Systematic Reviews of Interventions (5). Wiley-Blackwell, Chichester. https://doi.org/10.1002/9780470712184

[22] Pahor, M. and Cesari, M. (2012) Study Design: Randomized Controlled Trials. In: 
The Epidemiology of Aging, Springer, Berlin, 27-47. https://doi.org/10.1007/978-94-007-5061-6 3

[23] Bell, M.L., Kenward, M.G., Fairclough, D.L. and Horton, N.J. (2013) Differential Dropout and Bias in Randomised Controlled Trials: When It Matters and When It May Not. BMJ: British Medical Journal, 346, 8668.

https://doi.org/10.1136/bmj.e8668

[24] Gurusamy, K.S., Gluud, C., Nikolova, D. and Davidson, B.R. (2009) Assessment of Risk of Bias in Randomized Clinical Trials in Surgery. British Journal of Surgery, 96, 342-349. https://doi.org/10.1002/bjs.6558

[25] Higgins, J.P.T. and Altman, D.G. (2008) Assessing Risk of Bias in Included Studies. In: Higgins, J.P.T. and Green, S., Eds., Cochrane Handbook for Systematic Reviews of Interventions, Wiley, Hoboken, 187-241. https://doi.org/10.1002/9780470712184.ch8

[26] Hopewell, S., Clarke, M., Lusher, A., Lefebvre, C. and Westby, M. (2002) A Comparison of Hand-Searching versus MEDLINE Searching to Identify Reports of Randomized Controlled Trials. Statistics in Medicine, 21, 1625-1634. https://doi.org/10.1002/sim.1191

[27] Buscemi, N., Hartling, L., Vandermeer, B., Tjosvold, L. and Klassen, T.P. (2006) Single Data Extraction Generated More Errors than Double Data Extraction in Systematic Reviews. Journal of Clinical Epidemiology, 59, 697-703. https://doi.org/10.1016/j.jclinepi.2005.11.010

[28] Liberati, A., Altman, D.G., Tetzlaff, J., Mulrow, C., Gøtzsche, P.C., Ioannidis, J.P., Moher, D., et al. (2009) The PRISMA Statement for Reporting Systematic Reviews and Meta-Analyses of Studies That Evaluate Healthcare Interventions: Explanation and Elaboration. Annals of Internal Medicine, 151, 65. https://doi.org/10.7326/0003-4819-151-4-200908180-00136

[29] Eccles, M.P., Weijer, C. and Mittman, B. (2011) Requirements for Ethics Committee Review for Studies Submitted to Implementation Science. Implementation Science, 6, 32. https://doi.org/10.1186/1748-5908-6-32

[30] Kalichman, M.W. (2011) Overview: Underserved Areas of Education in the Responsible Conduct of Research: Authorship. Science and Engineering Ethics, 17, 335-339. https://doi.org/10.1007/s11948-011-9281-3

[31] Wager, E. and Wiffen, P.J. (2011) Ethical Issues in Preparing and Publishing Systematic Reviews. Journal of Evidence-Based Medicine, 4, 130-134. https://doi.org/10.1111/j.1756-5391.2011.01122.x

[32] Four Artemisinin-Based Combinations (4ABC) Study Group (2011) A Head-to-Head Comparison of Four Artemisinin-Based Combinations for Treating Uncomplicated Malaria in African Children: A Randomized Trial. PLoS Medicine, 8, e1001119. https://doi.org/10.1371/journal.pmed.1001119

[33] Yeka, A., Tibenderana, J., Achan, J., D’Alessandro, U. and Talisuna, A.O. (2013) Efficacy of Quinine, Artemether-Lumefantrine and Dihydroartemisinin-Piperaquine as Rescue Treatment for Uncomplicated Malaria in Ugandan Children. PLoS ONE, 8, 53772-53775. https://doi.org/10.1371/journal.pone.0053772

[34] Kapisi, J., Bigira, V., Clark, T., Kinara, S., Mwangwa, F., Achan, J., Dorsey, G., et al. (2015) Efficacy and Safety of Artemether-Lumefantrine for the Treatment of Uncomplicated Malaria in the Setting of Three Different Chemopreventive Regimens. Malaria Journal, 14, Article No. 53. https://doi.org/10.1186/s12936-015-0583-9

[35] Faye, B., Ndiaye, J.L., Tine, R., Sylla, K., Gueye, A., Lô, A.C. and Gaye, O. (2010) A Randomized Trial of Artesunate Mefloquine versus Artemether Lumefantrine for 
the Treatment of Uncomplicated Plasmodium falciparum Malaria in Senegalese Children. The American Journal of Tropical Medicine and Hygiene, 82, 140-144. https://doi.org/10.4269/ajtmh.2010.09-0265

[36] Maiga, H., Djimde, A.A., Beavogui, A.H., Toure, O., Tekete, M., Sangare, C.P.O., Doumbo, O.K., et al. (2015) Efficacy of Sulphadoxine-Pyrimethamine+ Artesunate, Sulphadoxine-Pyrimethamine+ Amodiaquine, and Sulphadoxine-Pyrimethamine Alone in Uncomplicated Falciparum Malaria in Mali. Malaria Journal, 14, 64-71. https://doi.org/10.1186/s12936-015-0557-y

[37] Nambozi, M., Van Geertruyden, J.P., Hachizovu, S., Chaponda, M., Mukwamataba, D., Mulenga, M., D’Alessandro, U., et al. (2011) Safety and Efficacy of Dihydroartemisinin-Piperaquine versus Artemether-Lumefantrine in the Treatment of Uncomplicated Plasmodium falciparum Malaria in Zambian Children. Malaria Journal, 10, Article No. 50. https://doi.org/10.1186/1475-2875-10-50

[38] Schramm, B., Valeh, P., Baudin, E., Mazinda, C.S., Smith, R., Pinoges, L., Guérin, P.J., et al. (2013) Tolerability and Safety of Artesunate-Amodiaquine and Artemether-Lumefantrine Fixed Dose Combinations for the Treatment of Uncomplicated Plasmodium falciparum Malaria: Two Open-Label, Randomized Trials in Nimba County, Liberia. Malaria Journal, 12, Article No. 250. https://doi.org/10.1186/1475-2875-12-250

[39] Whegang, S.Y., Tahar, R., Foumane, V.N., Soula, G., Gwét, H., Thalabard, J.C. and Basco, L.K. (2010) Efficacy of Non-Artemisinin- and Artemisinin-Based Combination Therapies for Uncomplicated Falciparum Malaria in Cameroon. Malarial Journal, 9, Article No. 56. https://doi.org/10.1186/1475-2875-9-56

[40] Faye, B., Offianan, A.T., Ndiaye, J.L., Tine, R.C., Touré, W., Djoman, K., Gaye, O., et al. (2010) Efficacy and Tolerability of Artesunate-Amodiaquine (Camoquin plus $^{\circledast}$ ) versus Artemether-Lumefantrine (Coartem ${ }^{\circledast}$ ) against Uncomplicated Plasmodium falciparum Malaria: Multisite Trial in Senegal and Ivory Coast. Tropical Medicine \& International Health, 15, 608-613.

https://doi.org/10.1111/j.1365-3156.2010.02487.x

[41] Fergusson, D., Aaron, S.D., Guyatt, G. and Hébert, P. (2002) Post-Randomisation Exclusions: The Intention to Treat Principle and Excluding Patients from Analysis. BMJ, 325, 652-654. https://doi.org/10.1136/bmj.325.7365.652

[42] Balk, E.M., Bonis, P.A., Moskowitz, H., Schmid, C.H., Ioannidis, J.P., Wang, C. and Lau, J. (2002) Correlation of Quality Measures with Estimates of Treatment Effect in Meta-Analyses of Randomized Controlled Trials. JAMA, 287, 2973-2982. https://doi.org/10.1001/jama.287.22.2973

[43] Siersma, V., Als-Nielsen, B., Chen, W., Hilden, J., Gluud, L.L. and Gluud, C. (2007) Multivariable Modelling for Meta-Epidemiological Assessment of the Association between Trial Quality and Treatment Effects Estimated in Randomized Clinical Trials. Statistics in Medicine, 26, 2745-2758. https://doi.org/10.1002/sim.2752

[44] Sodahlon, Y.K., Agbo, K., Morgah, K., Adjogble, K., Avodagbe, A., Djadou, K.E., Malvy, J.M., et al. (2003) Chloroquine Efficacy in the Treatment of Uncomplicated Malaria at Three Sentinel Sites in Northern Togo. Annals of Tropical Medicine and Parasitology, 97, 775-782. https://doi.org/10.1179/000349803225002471

[45] Ngasala, B.E., Malmberg, M., Carlsson, A.M., Ferreira, P.E., Petzold, M.G., Blessborn, D., Mårtensson, A., et al. (2011) Efficacy and Effectiveness of Artemether-Lumefantrine after Initial and Repeated Treatment in Children $<5$ Years of Age with Acute Uncomplicated Plasmodium falciparum Malaria in Rural Tanzania: A Randomized Trial. Clinical Infectious Diseases, 52, 873-882. 
https://doi.org/10.1093/cid/cir066

[46] Gbotosho, G.O., Folarin, O.A., Bustamante, C., da Silva, L.H.P., Mesquita, E., Sowunmi, A., Happi, C.T., et al. (2012) Different Patterns of pfcrt and pfmdr1 Polymorphisms in P. falciparum Isolates from Nigeria and Brazil: The Potential Role of Antimalarial Drug Selection Pressure. The American Journal of Tropical Medicine and Hygiene, 86, 211-213. https://doi.org/10.4269/ajtmh.2012.11-0368

[47] Gbotosho, G.O., Sowunmi, A., Happi, C.T. and Okuboyejo, T.M. (2011) Therapeutic Efficacies of Artemisinin-Based Combination Therapies in Nigerian Children with Uncomplicated Falciparum Malaria during Five Years of Adoption as First-Line Treatments. The American Journal of Tropical Medicine and Hygiene, 84, 936-943. https://doi.org/10.4269/ajtmh.2011.10-0722

[48] WHO (2011) World Malaria Report.

https://www.who.int/malaria/world malaria report 2011/en

[49] Oguche, S., Okafor, H.U., Watila, I., Meremikwu, M., Agomo, P., Ogala, W., Sowunmi, A., et al. (2014) Efficacy of Artemisinin-Based Combination Treatments of Uncomplicated Falciparum Malaria in Under-Five-Year-Old Nigerian Children. The American Journal of Tropical Medicine and Hygiene, 91, 925-935. https://doi.org/10.4269/ajtmh.13-0248

[50] Chotivanich, K., Udomsangpetch, R., Dondorp, A., Williams, T., Angus, B., Simpson, J.A., White, N.J., et al. (2000) The Mechanisms of Parasite Clearance after Antimalarial Treatment of Plasmodium falciparum Malaria. The Journal of Infectious Diseases, 182, 629-633. https://doi.org/10.1086/315718

[51] Gbotosho, G.O., Okuboyejo, T., Happi, C.T. and Sowunmi, A. (2014) Fall in Hematocrit per 1,000 Parasites Cleared from Peripheral Blood: A Simple Method for Estimating Drug-Related Fall in Hematocrit after Treatment of Malaria Infections. American Journal of Therapeutics, 21, 193-197. https://doi.org/10.1097/MJT.0b013e31822119d9

[52] Rolling, T., Wichmann, D., Schmiedel, S., Burchard, G.D., Kluge, S. and Cramer, J.P. (2013) Artesunate versus Quinine in the Treatment of Severe Imported Malaria: Comparative Analysis of Adverse Events Focussing on Delayed Haemolysis. Malaria Journal, 12, Article No. 241. https://doi.org/10.1186/1475-2875-12-241

[53] Owens, D.C. (2014) A Guide to the Extrapyramidal Side-Effects of Antipsychotic Drugs. Cambridge University Press, Cambridge.

https://doi.org/10.1017/CBO9781139149112 